\title{
An Assessment of the Functional Properties, Proximate Composition, Sensory Evaluation and Rheological Value of Gari Fortified with Bambara Groundnut Flour (Voandzeia Subterranean Thouars)
}

\author{
Bankole ${ }^{1}$, Y.O. \\ Tanimola ${ }^{1}$, O.A. \\ Odunukan ${ }^{1}$, R.O. \\ Samuel $^{2}$, D.O. \\ ${ }^{1}$ Department of Agricultural Engineering; School of Engineering, \\ Lagos State Polytechnic, Ikorodu-Nigeria \\ ${ }^{2}$ Department of Food Technology; School of Technology, \\ Lagos State Polytechnic, Ikorodu-Nigeria
}

\section{Doi:10.5901/ ajis.2013.v2n10p165}

\section{Abstract}

Gari fortified with Bambara Groundnut Flour (BGF) was assessed for its proximate composition, functional properties, sensory evaluation and Rheological properties. Four samples; $100 \%$ gari (coded SLY), 90\% gari with 10\% BGF (coded ATS), 85\% gari with 15\% BGF (coded FEA), and $80 \%$ gari with 20\% BGF (coded ROT) were examined for the parameters listed above. The proximate analysis showed that the protein content ranges between $0.98 \%-4.68 \%$, fat content $1.10-2.60 \%$, ash content $1.82-2.90 \%$, crude fibre $2.30-2.42 \%$. This showed an increase on addition of BGF while the carbohydrate content ranges between $78.20 \%$ - $83.5 \%$, moisture $11.60 \%-12.60 \%$ and acidity $0.40-0.60$, all showed a decrease in value on adding BGF. Rheological value showed that the peak viscosity ranges between 106.17 - 177.17, trough viscosity 98.33 - 161.00, breakdown 7.83 - 16.71, final viscosity 150.50 - 251.67, set back 52.17 - 90.67 and pasting time between 6.87 - 6.93. All these varied inversely with the quantity of BGF added. Pasting temperature showed slight variation which was not dependent on the amount of BGF added. It ranges from 79.2 - 80.020C. Sensory evaluation showed that there were significant differences in the samples examined

Keywords: Gari, Bambara-groundnut, proximate composition, sensory evaluation, Rheological value.

\section{I ntroduction}

Cassava (Manihot esculenta crantz) provides energy as a dominant staple food crop of great importance for the nutrition of over 500 million people in the tropical world most especially in Africa and in many developing countries. Irtwange and Achimba (2009) viewed that cassava appears to be the major staple food that matches the population growth in Nigeria. It is an important raw material for the non-food industries as well. The low amylase, high amyl pectin content of the cassava starch gives it necessary viscosity for high quality adhesive and for use in paper and textile industries. Cassava also finds application in the production of dextrin utilized in glues and in the production of ethyl alcohol. There are two varieties of cassava, the bitter cassava and sweet cassava. The sweet cassava Manihot palamata can be boiled, pounded and eaten with soup. It is recognized by its red leaf and purplish outer cortical layer. The bitter cassava contains more bitter 
juice in its roots. The root is poisonous when eaten raw, so, it has to be fermented before use.

Gari is one of the numerous products derived from cassava tubers; the products derived from cassava include Fufu, Lafun, Starch, Tapioca, Cassava chips. The cassava roots are peeled, washed, grated, fermented, press, fry, sieved and bagged. If the process of hydrogen cyanides extraction in cassava is ensured. During fermentation, some micro-organisms such as Corynebacterium and Lactobacillus spp would breakdown the cyanohydrins produced during the hydrolysis to ketone and hydrogen cyanide. Consequently, in aerobic fermentation, pyruvic acid is broken down by a large number of steps into carbon dioxide and water, a process which yields a lot of energy. In anaerobic fermentation, few steps are involved and only pyruvic acid is incompletely broken down yielding the end product which is carbon dioxide, alcohol, lactic acid with other organic acids and a small amount of energy. Irtwange and Achimba (2009) stated that fermentation is carried out to detoxify the cassava and to develop the characteristics flavor.

Bambara groundnut crops are mostly herbaceous plants from the family of legume. It is an important item in the diet of West African. It is a source of plant protein. It can be consumed boiled after freshly harvested roasted and eaten with palm kernel as a snack when dry (Alozie, et al 2009). Ijarotimi and Keshinro (2012) revealed that protein-energy malnutrition among children is the major health challenges in developing countries particularly Nigeria. BGF is eaten in various ways, either alone or mixed with maize, rice, fish or gari. Bambara groundnuts are sometimes grown as cover crops because it is valuable for improving soil fertility. Bambara contain 7.3\% moisture, 18 to $24 \%$ protein, 6.0 to $6.5 \%$ fat and 60 to $63 \%$ carbohydrates (Eltayeb, et a/ 2012). The immature seeds are boiled and eaten as an early harvested source of food and the fully matured seeds are cooked or made into flour. It is cultivated both as an intercrop with maize, cowpea, melon or as a sole crop.

Gari has a very low level of protein probably because of this; kwashiorkor is believed to be prevalent in the area where cassava is the staple items of diet. With the prevalence of malnutrition in the society, there is need to fortified our diets with protein using a cheap source of protein that is found in legume family. The purpose of this study is to reduce kwashiorkor; a prominent diseases of people that lack protein and also allow for maximum utilization of local raw materials. It will also aid the sensitization of Millennium Development Goals and aid Federal Government policy on food fortification campaign. Therefore, specific objectives are:

1. To produce fortified gari with bambara groundnut flour.

2. To evaluate the effects of fortification on the nutritional composition of the product.

3. To determine the functional properties and rheological properties of the product.

\section{Methods and Procedure}

Bambara Groundnut was purchased at mile 12 market in Lagos state and the cassava was purchased from a farm at Ogijo, Ogun State. Cassava tubers were washed, to remove the surface dirt and surface micro-organisms. Tubers were then peeled and grated to reduce the size and to determine the size of the end products. Pulp formed was fermented for $5 /$ days for proper lactic acid fermentation to take place and reduce the toxic level and serve as a means of preservation due to reduction in $\mathrm{pH}$. Fermented pulp was then dewatered to remove excess water, sieved and fried to reduce water content and give good taste and also to remove the Hydrogen Cyanide which is volatile in nature.

\subsection{Flow Chart for the Production of Fortified Gari with Bambara Groundnut}




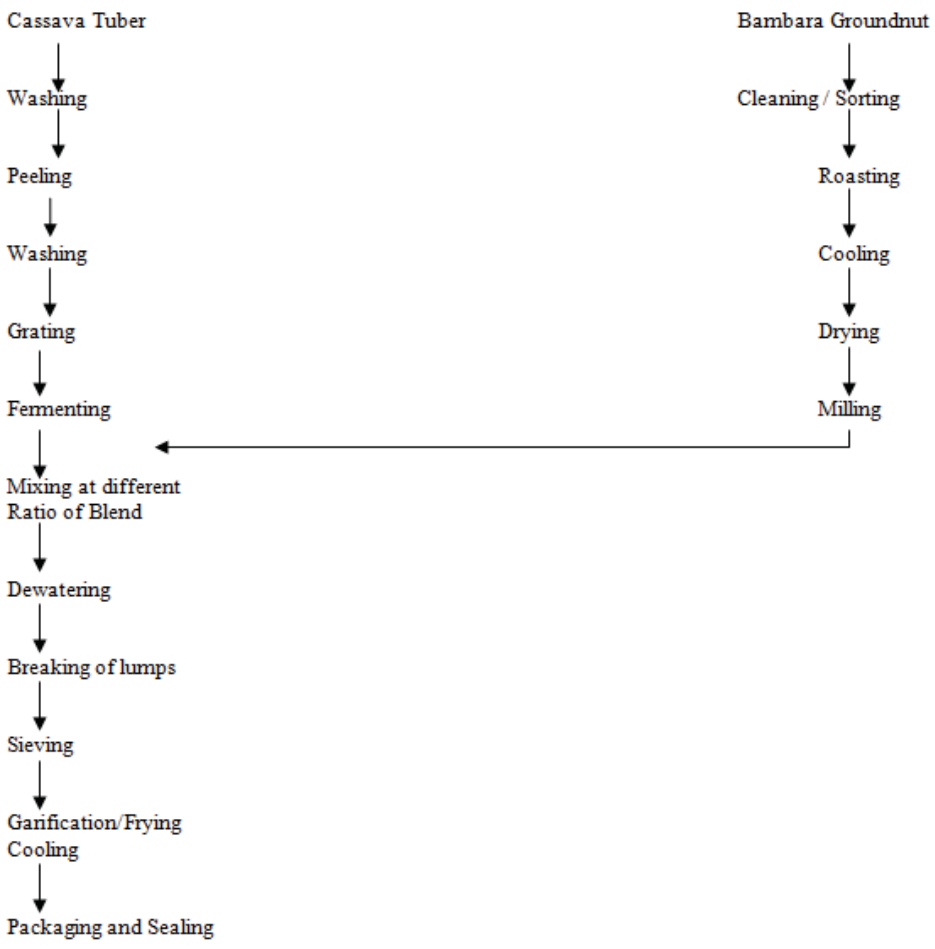

\subsection{Functional/Physical Properties Determination}

Functional properties were carried out to determine the behavioral and physical characteristics of the fortified gari. The parameter used include: Water absorption capacity, bulk density, swelling index.

\subsubsection{Water Absorption Capacity Determination (WAC)}

3grams of each sample were weighed into different centrifugal tube of known weight. 10ml of distilled water was added and samples were stirred. Tubes were then placed in water bath at room temperature $32^{\circ} \mathrm{C}$ for $30 /$ minutes and they were stirred at 10 minutes intervals. Tubes were centrifuge at $250 \mathrm{rpm}$ for $15 /$ minutes. Supernatant was decanted and the tubes containing the samples were reweighed.

Calculation:

WAC

$$
=\quad \frac{\text { weight of sample }+ \text { test }}{\text { test tube after experiment }}-\frac{\text { weight of sample }+ \text { test }}{\text { test tube before experiment }}
$$

\subsubsection{Bulk Density}

2grams of each sample were weighed and poured into $100 \mathrm{ml}$ measuring cylinder. The cylinder was tapped constantly against a table until there was no further change in volume. The level of the sample was then traced.

Calculation:

Bulk density

$$
=\quad \text { Mass } / \text { Volume }\left(\mathrm{gcm}^{-3}\right)
$$




\subsubsection{Swelling Index Determination}

2 grams of each sample were weighed and placed in $100 \mathrm{ml}$ of distilled water at $50^{\circ} \mathrm{C}$ in a graduated measuring cylinder. It was tapped gently to eliminate air and the volume was noted in Cylinder. The mixture was allowed to swell and then swirl round and then it was allowed to stand for 1 hour and final volume was noted.

Calculation

Swelling index $=\frac{\text { final volume-initial volume }}{\text { sample }}$

\subsection{Chemical or Proximate Analysis}

Chemical or proximate analysis was used to determine chemical composition of each of the food formula. The analyses according to Eltayeb et al (2012) include the determination of Moisture content, $\mathrm{pH}$ value, Total titration acidity, Ash determination, Protein, Crude fiber and carbohydrate content.

\subsubsection{Moisture Content Determination}

Moisture meter as used. The device mechanism is based on drying of the sample at $100^{\circ} \mathrm{C}$ for 10minutes.

\subsubsection{Procedure:}

The device (moisture analyzer) was connected to switch, when the switch was on, the device indicated ready on its screen, sample was added on the foil plate in it, and the cover lid was closed. At 10 minutes, the device indicated the end of the analysis by displaying the moisture content in percentage on its screen.

\subsubsection{Carbohydrate Determination}

Total carbohydrate content of each samples were determined by difference. These were done by subtracting the percentage of moisture, ash, protein and fat obtained from $100 \%$ (Bryant et al, 1988).

Calculation:

$\%$ Carbohydrate $\quad=\quad 100 \%-($ moisture + ash $+\%$ protein + fat $)$

\subsubsection{Ash Content Determination}

Ash content determination was based on principle of complete incineration of organic component of food and the left behind component is called inorganic component or ash.

\subsubsection{Apparatus}

Crucibles to be used were cleaned, dried by being ignited and cooled in desiccators and weighed $5 \mathrm{~g}$ of samples were introduced into the crucibles and the initial weight was taken. The crucible and its content were placed over a burner flame until the samples in it turns brown. The crucibles and their contents were then transferred, using a pair of cleaned tongs into a muffle furnace at $600^{\circ} \mathrm{C}$ for lhour or until fully ash.

The crucibles and their contents (residue) were placed in the desiccators for cooling and weighed. 
Calculation:

$\frac{\% \text { Ash weight of residue }}{\text { weight of sample }} \times 100$

\subsubsection{PH Determination}

$5 \mathrm{grams}$ of each sample were dissolved in $100 \mathrm{ml}$ distilled water. The samples were centrifuged for 15 minutes. The $\mathrm{pH}$ of the decanted resulting solution was determined with the aid of a previously standardized $\mathrm{PH}$ meter (Unicans 945 model). Already calibrated $\mathrm{pH}$ meter with $\mathrm{pH}$ of 4.0 and 7.0 buffers. The $\mathrm{pH}$ electrodes were then introduced into the sample and the readings indicated on the screen.

\subsubsection{Total Acidity}

Acidity of each sample was determined by the titration of $25 \mathrm{ml}$ of the decanted homogenate used for $\mathrm{pH}$ determination against $0.1 \mathrm{~m} \mathrm{NaOH}$ to $\mathrm{pH} 8.3$.

The relative amount of lactic acid was calculated as percentage lactic acid on dry matter basis as follows.

Calculation

$\%$ lactic acid $\quad=\quad \frac{\text { Titer value } \times \text { Nomality of alkalis }}{\text { weight of sample }} \times 100$

\subsection{Crude Fibre Determination}

$10 \mathrm{~g}$ of each samples were weighed into a $250 \mathrm{ml}$ conical flask, $50 \mathrm{ml}$ of $0.3 \mathrm{~m} \mathrm{H}_{2} \mathrm{SO}_{4}$ was added and the mixture reflux for half an hour using reflux condenser $0.5 \mathrm{~m}$ Sodium hydroxide was added after the half hour and refluxing was carried out for another half an hour. (Defatted sample obtained). Content in the flask was filtered using filter paper. Residue was rinsed with hot water and this followed with addition of $50 \mathrm{ml}$ acetone to remove any fat present. Fibre was then scrap into a crucible using a jet of acetone from the filter paper into a cleaned, weighed crucible. Acetone was evaporated by heating crucible over a boiling water bath. The sample was dried in a convectional oven for 1 hour at $140^{\circ} \mathrm{C}$. The fibre was further ash in furnace at $600^{\circ} \mathrm{C}-650^{\circ} \mathrm{C}$ for 3 hours. Sample was cooled in desiccators and weighed after cooling. Same procedure was repeated for other samples.

\subsection{Protein Determination}

Protein content in food samples is determined mainly or usually by the conventional Kedjhal method. However, various modifications are available and one of them is Nessler's Reagent Method where $5 \mathrm{~g}$ of the sample was weighed and transferred into a digestion flask. $5 \mathrm{ml}$ of the concentrated $\mathrm{H}_{2} \mathrm{SO}_{4}$ was added. The sample and the acid were heated gently until digestion is completed. This was determined when the solution became clear. The digest is finally clarified by adding another strong oxidizing agent, hydrogen peroxide $\left(\mathrm{H}_{2} \mathrm{SO}_{4}\right)$. The solution becomes very clear signifying total digestion. Digest was then transferred into a $100 \mathrm{ml}$ volumetric flask and made to volume with ammonia free water to form a stock solution. $10 \mathrm{ml}$ of the aliquot was transferred into another $25 \mathrm{ml}$ volumetric flask and $2 \mathrm{ml}$ of Nessler's reagent was added. The mixture was made up to volume with ammonia free water. Change in colour from yellow to brown was observed, which shows the presence of Nitrogen. The intensity of the colour is directly proportional to the amount of Nitrogen in the sample which is also related to the quality of protein in the sample. Color 
developed was measured using spectrophotometer at about 460 - 462 nanometer, from which the amount of protein was determined.

\subsection{Fat Content Determination}

$10 \mathrm{~g}$ of each sample was put into cleaned, dried conical flask. Samples were heated with $10 \mathrm{ml}$ alcohol for 10 minutes on a water bath at a temperature $62^{\circ} \mathrm{C}$. Samples were allowed to cool using desiccators.

$12 \mathrm{ml}$ diethyl ether was added into sample in each flask, samples and the reagent were shake properly. $0.5 \mathrm{ml}$ dilute ammonia was added to the samples in each flask. $4.5 \mathrm{ml}$ water and $12.5 \mathrm{ml}$ light petroleum was added and were mixed together gently.

Upper layer of each sample was siphoned off into a cleaned weighed beaker. Extract were then heated to remove solvent by evaporation and were then weighed and values were recorded.

Calculation

$\%$ fat content $=\frac{\text { weight of extract }}{\text { weight of sample }} \times 100$

\subsection{Sensory Evaluation}

Sensory evaluation was performed on each of the formulation to evaluate their organoleptics qualities. The samples were reconstituted with boiled water. A sensory panelist of 9 people was used. The formulations were assessed in term of color, taste, aroma and general acceptability using a nine (9) point hedonic scale as shown below.

Like extremely; Like very much; Like moderately; Like slightly; Neither like nor dislike; Dislike slightly; Dislike moderately; Dislike very much; Dislike extremely.

Samples were presented to each panelist in a clean saucer in warm form. Coded name was placed below each saucer used to serve the panelist.

\subsection{Rheological Properties}

Rapid Visco Analyser model RVA-3D was used to determine the peak viscosity peak time, pasting temperature, peak temperature, holding strength, Breakdown, final viscosity, set back from peak and pasting time of the samples.

\subsubsection{Operation and General Principle}

The Rapid Visco Analyser was designed as a simple - to - use viscometer. Sample preparation requirement have been minimized and the test procedure is highly automated. Proper operation of the instrument depends on the actual application required. Successful analysis generally depends on proper application of a few general principles and following a few simple steps. Generally, method employed for testing depends on the nature of the sample being analyzed; diversity of the samples and application makes it impractical to detail a method for every sample. However, a few general principles can be applied to majority of the cases. The types of test employed can vary widely depending on whether it is for process emulation, rapid screening, quality control, basic research and so on.

\subsubsection{Procedure}

The device was switched to on position. $3 \mathrm{~g}$ of each samples was transferred into the water surface in the canister. The paddle was placed into a canister and the blade was vigorously jogged through the sample up and down ten times, or until the flour was no longer found on the surface of the water. The device automatedly recorded on the chat the value of the gelatilization temperature and 
viscosity at different stages of heating. The device automatedly plotted a chart which was shown on the computer screen.

\subsubsection{Definition of Terms Used in Rheological Value}

a. Peak Visocity: Maximum viscosity developed during or soon after the heating portion of the test, in RVU

b. Peak Time: Time at which the peak viscosity occurred, in minutes.

c. Peak Temperature: Temperature at which the peak viscosity occurred in ${ }^{0} \mathrm{C}$.

d. Pasting Temperature: Temperature where viscosity first increases by at least 2RVU over a 20seconds. Period using profile STD 1 , in ${ }^{0} \mathrm{C}$.

e. Holding Strength: Minimum viscosity after the peak, normally occurring around the commencement of sample cooling, in RVU.

f. Breakdown: Peak viscosity minus trough viscosity in RVU

g. Final Viscosity: Viscosity at the end of the test, in RVU

h. Setback From Peak: Final viscosity minus peak viscosity in RVU

i. Setback From Tough: Final viscosity minus trough viscosity in RVU

These values can conveniently be determined by using the software provided with the instrument.

\section{Results}

The results obtained were as presented in tables 1, 2, 3 and 4

Table 1. Result for functional properties.

\begin{tabular}{|l|c|c|c|c|}
\hline \multicolumn{1}{|c|}{ Functional } & \multicolumn{4}{c|}{ Samples Code } \\
\hline \multicolumn{1}{|c|}{ Properties } & SLY & ATS & FEA & ROT \\
\hline${\text { Bulk density }\left(\mathrm{gcm}^{-3}\right)}^{\text {S }}$ & 0.625 & 0.606 & 0.615 & 0.625 \\
\hline Swelling index & 5.00 & 3.00 & 4.20 & 4.50 \\
\hline Water Absorption Capacity & 6.53 & 5.53 & 5.10 & 4.83 \\
\hline
\end{tabular}

Table 2. Result for proximate composition

\begin{tabular}{|l|c|c|c|c|}
\hline Proximate Composition & SLY & ATS & FEA & ROT \\
\hline Moisture context (\%) & 12.60 & 12.20 & 11.38 & 11.60 \\
\hline Protein content (\%) & 0.98 & 2.98 & 3.39 & 4.68 \\
\hline Fat content (\%) & 1.10 & 1.32 & 1.88 & 2.60 \\
\hline Ash content (\%) & 1.82 & 2.20 & 2.60 & 2.80 \\
\hline Carbohydrate content (\%) & 83.5 & 81.30 & 79.86 & 78.20 \\
\hline Crude fibre (\%) & 2.30 & 2.26 & 2.42 & 2.31 \\
\hline pH & 4.30 & 4.50 & 4.93 & 4.90 \\
\hline Acidity & 0.64 & 0.43 & 0.43 & 0.40 \\
\hline
\end{tabular}

Table 3. Results for sensory evaluation

\begin{tabular}{|c|c|c|c|c|c|c|}
\hline & \multicolumn{6}{|c|}{ F-tabulated } \\
\hline Source of Variance & df & ss & mss & Fcal & @5\% level & @ 1\% level \\
\hline Colour & 35 & 32.89 & 4.44 & 7.71 & 9.03 & 14.16 \\
\hline Taste & 35 & 137.11 & 20.54 & 14.55 & 9.03 & 14.16 \\
\hline Texture & 35 & 87.94 & 12.16 & 12.45 & 9.03 & 14.16 \\
\hline
\end{tabular}




\begin{tabular}{|l|l|l|l|l|l|l|}
\hline Flavor & 35 & 184.00 & 28.24 & 15.27 & 9.03 & 14.16 \\
\hline General acceptance & 35 & 208.67 & 29.04 & 50.34 & 9.03 & 14.16 \\
\hline
\end{tabular}

Table 4. Result for rheological value

\begin{tabular}{|l|c|c|c|}
\hline \multicolumn{1}{|c|}{ SLY } & ATS & FEA & ROT \\
\hline Peak Viscosity 177.17 & 136.50 & 135.42 & 106.17 \\
\hline Trough Viscosity 161.00 & 127.00 & 126.25 & 98.33 \\
\hline Breakdown 16.17 & 9.50 & 9.17 & 7.83 \\
\hline Final Viscosity 251.67 & 191.50 & 175.75 & 150.50 \\
\hline Set Back 90.67 & 64.50 & 49.50 & 52.17 \\
\hline Peak time (minute) 6.93 & 6.07 & 6.93 & 6.87 \\
\hline Pasting Temperature $\left({ }^{\circ} \mathrm{C}\right) 79.20$ & 80.02 & 77.83 & 78.55 \\
\hline
\end{tabular}

\section{Discussion}

\subsection{Function Properties}

Sample SLY had the highest water absorption capacity (WAC) and Swelling index. Water absorption capacity (WAC) is an important parameter which can be used to determine cooking time. Sample SLY will therefore be expected to give the shortest cooking time which implies less fuel and energy. Sample SLY and ROT had the highest bulk density while sample ATS had the lowest.

\subsection{Proximate Composition}

The results of the chemical composition of all the fortified gari using bambara groundnut were as shown. Protein content is one of the most important parameters determined. Protein content of the fortified gari ranged from SLY sample 0.98\% (Gari 100\%, Bambara groundnut 0\%) to ATS sample 2.98\% (Gari 85\%, Bambara groundnut 15\%) and to ROT sample 4.68\% (Gari 80\%, Bambara groundnut $20 \%$ ) Ash content, which is an estimation of mineral content of the fortified sample ranged from $(1.82 \%-2.8 \%)$. This is an indication that the samples contain a fair source of mineral element required by the body. Fat content of the samples ranged from $1.10 \%-2.60 \%$. The result revealed that fortification of each samples helped to enhance the fat content of the sample.

Moisture content ranges from $11.60 \%-12.60 \%$. Low moisture content ensures longer shelf life.

Carbohydrate content decreases as the Bambara Groundnut flour was being increased.

Sample SLY has 83.5\% (Gari 100\%, Bambara 0\%) to sample FEA 79.86\% (Gari 85\%, Bambara 15\%) and to sample ROT 78.20\% (Gari 80\%, Bambara 20\%). pH of the samples were relatively low, which ranges from (4.30 - 4.90). Low PH ensures good keeping quality of any sample (Akapo et al, 1995). Acidity of the four samples were relatively low. Low acidity ensures long shelf life of the product

\subsection{Sensory Evaluation}

Results of the sensory evaluation carried out on the samples were as shown in Table 4. The raw data was analyzed using Analysis of variance (ANOVA) to determine any significant difference among the samples. The result showed significant difference at $5 \%$ level and $1 \%$ level in taste, color, flavor and general appearance. But there is no significant difference in the texture at $1 \%$ significant level. 


\subsection{Rheological Value}

The results of the rheological study using Rapid viscous Analyzer - 3D showed that the value for peak viscosity, Trough viscosity, Breakdown, final viscosity, set back, and pasting time was inversely proportional to the quantity of bambara groundnut flour added, that is, the values obtained reduce with increase in the quantity of bambara groundnut contained in the sample. This is evident with sample SLY (100\% gari and $0 \%$ Bambara groundnut) having the highest value, followed by sample ATS ( $90 \%$ Gari and 10\% bambara groundnut), FEA ( $85 \%$ Gari and 15\% Bambara Groundnut) and ROT (80\% Gari and 20\% Bambara Groundnut) having the least value. The result showed that the water binding capacity and swelling ability of the sample reduce as the value of bambara groundnut increases.

However, the pasting temperature showed slight variation which was not dependent on the amount of bambara groundnut flour added.

\section{Conclusion}

The study has shown that protein can be included in gari production using bambara groundnut flour. The nutritional content of the fortified Bambara gari is improved, as there is an increase in protein content, fat content, and ash content, but decrease in carbohydrate content on addition of bambara groundnut flour to the gari at different percentage. Result of the sensory evaluation carried out on the samples shows an average acceptability of the samples. The preference for the sample decreases as the incorporation of the bambara groundnut flour increases.

It is, however, noted from the study that protein fortification of gari with bambara flour affect significantly the colour, taste, flavour and general appearance of the sample. Therefore, the production of bambara-garri production is much easier to produce because it is less labour intensive and with very low cost of production.

\section{Recommendation}

Incorporation of bambara groundnut flour in gari production for protein inclusion should not be more than $5 \%$ as increase in this will affect the color, taste flavor and general appearance of the garri. It should, however, be included that another source of protein such as fish and meat be consumed with fortified garri using Bambara groundnut to ensure proper amount of protein required in the diet to prevent kwashiorkor in the society.

\section{Reference}

Alozie, Y.E., Iyam, M.A., Lawal, O., Udofia, U. and Ani, I.F. (2009). Utilization of Bambara groundnut flour blends in bread production. Journal of Food technology. Vol. 7 (4) pp. 111-114

Eltayeb, A.R., Ali, A.O., Abou-Arab, A. and Abu-Salem, F.M. (2011). Chemical composition and functional properties of flour and protein isolate extracted from Bambara groundnut (Vigna subterranean). African Journal of Food Science. Vol. 5 (2), pp. 82-90. Available online; http://www.academicjournals.org/ajfs ISSN 1996-0794(c)2011 Academic J ournals

Ijarotimi, O.S. and Keshinro, 0.0. (2012). Formulation and Nutritional Quality of Infant Formula Produced from Germinated Popcorn, Bambara Groundnut and African Locust Bean Flour. Journal of Microbiology, biotechnology and Food Sciences: 1 (6) 1358-1388

Irtwange, S. and Achimba, O. (2009). Effect of the Duration of Fermentation on the Quality of Gari. J ournal of Biological Sciences 1 (3): 150-154

Pederson, C.S. (1978) Microorganism of fermented Food in Microbiology of Food Fermentation 2nd Edition, Page 39-42, 69-80. Ari Publisher, Connecticut, United State of American 
